\title{
How to Avoid Plagiarism
}

\author{
VIROJ WIWANITKIT ${ }^{1,2,3,4}$ \\ ${ }^{1}$ Wiwanitkit House, Bangkhae, Bangkok, Thailand; ${ }^{2}$ Hainan Medical University, Haikou, China; ${ }^{3}$ Joseph Ayobabalola \\ University, Ikeji-Arakeji, Nigeria; and ${ }^{4}$ Faculty of Medicine, University of Nis, Niš, Serbia
}

(Received 15 October 2012; accepted 17 October 2012; published online 26 October 2012)

Associate Editor K. A. Athanasiou oversaw the review of this article.

Sir, the recent article on plagiarism avoidance is very interesting. ${ }^{1}$ It is wise to avoid plagiarism in any writing. The first important thing is the intention on "not to steal or copy" the other's work and "not to duplicate" your own work. The proposed simple rules by Ober et al. can be useful. Here, the author would like to add more things that can increase the ability to avoid plagiarism. It should be noted that one might have the same idea and express in the same writing with the others. Therefore, an additional important thing to do is to recheck the work before submission it publication. The pre-submission screening for plagiarism is an important step that should be done. ${ }^{2}$ There are many good online available checking tools that can be selected for screening (such as Turnitin, eTBLAST, etc.). Screening by more than one tool to recheck the work for free of plagiarism can add guarantee for free of plagiarism.

\section{CONFLICT OF INTEREST}

None.

\section{REFERENCES}

${ }^{1}$ Ober, H., S. I. Simon, and D. Elson. Five simple rules to avoid plagiarism. Ann. Biomed. Eng. 2012 Sep 28.

${ }^{2}$ Wiwanitkit, V. Plagiarism: pre-submission screening. Perspect. Clin. Res. 2(4):149-150, 2011.
Address correspondence to Viroj Wiwanitkit, Wiwanitkit House, Bangkhae, Bangkok, Thailand. Electronic mail: wviroj@yahoo.com 